\title{
EFEKTIFITAS PERAN GURU PADA DETEKSI DINI SUSPECT FLATFOOT DI SEKOLAH DASAR KECAMATAN NGEMPLAK
}

\author{
Alfan Zubaidi, Sri Surini Pudjiastuti \\ Kementerian Kesehatan Politeknik Kesehatan Surakarta Jurusan Ortotik Prostetik
}

\begin{abstract}
The role of teacher, Flatfoot, Dynamic Balance. Children are growing well of motoric and sensoric activities. Their activities always use of lowerlimbs (legs). A problem which often rise on foot is flat foot. The purpose of this research is to know the effectiveness of the role of teachers in early detection of suspect flatfoot. this study is quasi experiment, with one gruop pre and post test design, variable in this study consists of the role of teacher effectiveness and early detection of flatfoot. This study was conducted in SDN Giriroto I, SDN Sindon I, and SDN III Manggung. Subjec of this study 32 teacher and 32 students (ages $6-8$ years). Instrument in this study are Foot print and stopwatch. Data analysis using linear Regression and T tests. There wasthe influence of the teacher's role by administering the intervention ( $p$ value $0.000<0.05$ ). There is the influence of dynamic balance by administering the intervention ( $p$ value $0.000<0.05$ ). Linear regression test results obtained niali $\rho=0.016$ indicates that there is a significant influence on the effectiveness of the role of the teacher towards early detection of flat foot. The effectiveness of the role of teachers affected by the grant of training on early detection offlat foot.
\end{abstract}

Key word: The role of teacher,Flatfoot, Dynamic balance

Abstrak : Peran Guru, Flatfoot, Keseimbangan Dinamis. Masa anak-anak adalah masa tumbuh kembang senso motorik dimana aktifitas kerja otot mengalami fase pertumbuhan optimal. Aktifitas anak lebih banyak menggunakan anggota gerak bawah (kaki). Masalah yang sering timbul pada kaki diantaranya adalah flat foot. Tujuan penelitian ini untuk mengetahui efektifitas peran guru dalam deteksi dini suspect flatfoot. Jenis penelitian ini adalah quasi eksperimen dengan one group pre and post test without control design, variabel penelitian ini terdiri keefektifan peran guru dan variabel deteksi dini flatfoot. Penelitian ini dilakukan di SDN Giriroto I, SDN Sindon I dan SDN III Manggung. Sampel penelitian ini 32 guru kelas dan 32 siswa usia $6-8$ tahun. Instrument dalam penelitian ini Foot print dan stopwatch. Analisis data menggunakan uji $\mathrm{T}$ dan Regresi linear. Terdapat pengaruh peran guru dengan pemberian intervensi ( $p$ value $0,000<0,05$ ). Terdapat pengaruh keseimbangan dinamis dengan pemberian intervensi $(p$ value $0,000<0,05$ ). Hasil uji regresi linear didapat niali $\rho=0,016$ menunjukkan bahwa terdapat pengaruh yang signifikan efektifitas peran guru terhadap deteksi dini flat foot. Efektifitas peran guru dipengaruhi oleh pemberian pelatihan tentang deteksi dini flat foot.

Kata Kunci : Peran Guru, Flatfoot, Keseimbangan Dinamis 


\section{PENDAHULUAN}

Masa anak-anak adalah masa tumbuh kembang senso motorik dimana aktifitas kerja otot mengalami fase pertumbuhan optimal, anak lebih aktif, lebih banyak bergerak, seperti bermain, berlari-lari, melompat, menari, dan lainlain. Aktifitas anak-anak tersebut lebih banyak menggunakan anggota gerak bawah dan kaki merupakan bagian yang berfungsi untuk menopang berat badan. Jika penopang itu tak kokoh, bukan tidak mungkin tubuh sering jatuh dan akhirnya merusak bangunan tubuh secara keseluruhan. Banyak yang mengalami masalah pada kaki diantaranya adalah flat foot. Flat foot yaitu tidak adanya lengkung kaki atau kaki datar (Ariani, 2014).

Flat foot merupakan suatu kondisi kaki dimana lengkungan telapak kaki rata, sehingga keseluruhan permukaan telapak kaki menyentuh tanah. Kondisi ini terjadi karena arkus atau lengkung pada telapak kaki lemah dan tidak terbentuk sempurna. Gejala yang ditemukan adalah kaki menapak pada aspek medial (Pronasi) sehingga anak merasa tidak nyaman saat berjalan dan cepat lelah ( Ferry, 2006).

Pendapat yang lain mengatakan bahwa kondisi ini muncul akibat kelemahan dari kapsul sendi dan ligament yang menopang persendian kaki, yang memungkinkan lengkung kaki menjadi turun ketika menahan berat badan (Michelson dkk, 2002), hal ini akan mengakibatkan gangguan kemampuan jalan dan cepat capai pada anak. Menurut Evans $20-30 \%$ anak di dunia mengalami Flat foot.

Prevalensi kejadian flat foot pada usia 6 tahun adalah $24 \%$. Sebagian besar anak akan menunjukkan perkembangan normal dari telapak kaki secara utuh pada usia 10 tahun (Sullivan J A 1999). Pada usia ini terjadi fase perkembangan fungsi motorik kasar dimana apabila terjadi kelemahan ligament, kelemahan otot pada kaki terutama otot tibialis anterior akan menyebabkan terjadi penurunan arcus kaki dan dapat mengganggu aktifitas anak. Pada usia ini juga terjadi perkembangan aktifitas seperti bermain, memanjat, berlari, menendang dan aktivitas bermain yang lain. Untuk dapat beraktifitas seperti itu diperlukan fungsi koordinasi, kemampuan motorik, keseimbangan, kelenturan dan kelincahan yang optimal..

Anak laki2 cenderung lebih besar mengalami kaki datar dibanding anak perempuan. Prevalensi kaki datar flexible sebanyak $52 \%$ dan $36 \%$ untuk anak perempuan. Penelitian flat foot di India menemukan bahwa prevalensi kaki datar pada anak usia usia 3 - 6 tahun adalah 44 $\%$. Selain mempengaruhi kemampuan berjalan, keseimbangan dinamis juga ditemukan rasa sakit pada telapak kaki saat berjalan, anak menjadi tidak tahan berjalan dalam waktu yang lama, mudah lelah dan anak akan malas beraktifitas atau bermain.

Menjadi Guru adalah suatu pekerjaan mulia, terhormat. Guru adalah pekerjaan profesional, artinya jabatan ini memerlukan suatu keahlian khusus. Dalam suasana di dalam kelas, di mana siswa bermacam-macam latar belakang minat dan kebutuhannya maka harus sanggup merangsang para peserta didik belajar, menjaga disiplin kelas, melakukan supervisi belajar dan memimpin para peserta didik untuk belajar sehingga proses pembelajaran berjalan baik dan memberikan hasil yang memuaskan (Murti, 2015).

Dalam kamus ilmiah populer kata peran adalah laku, hal berlaku atau tindak. 
Menurut Soerjono Soekanto peran sebagai aspek yang dinamis dari kedudukan, apabila seseorang melaksanakan hak-hak dan kewajiban sesuai dengan kedudukan maka seseorang itu menjalankan suatu peran.

Mengingat pentingnya kesehatan kaki bagi anak-anak dalam masa tumbuh kembang maka dirasa perlu untuk melakukan upaya-upaya dalam pencegahan dan deteksi dini akan terjadinya gangguan pada kaki khususnya flat foot sebelum memasuki usia 10 tahun.

Upaya deteksi dini dapat dilakukan oleh orang tua dan juga para guru yang mengasuh anak-anak di sekolah. Apabila para orang tua dan guru mempunyai pengetahuan dan ketrampilan yang cukup tentang deteksi dini flat foot, harapannya dapat berperan aktif dalam upaya pencegahan kasus ini di masyarakat. Dampak positifnya adalah anak sebagai generasi penerus bangsa mempunyai kapasitas fisik yang sempurna tumbuh menjadi anak cerdas yang aktif, trampil dan trengginas..

Peran guru terhadap deteksi dini kaki datar/flatfoot usia sekolah adalah mendeteksi aktifitas kesehariannya di lingkungan sekolah, mendata serta memberikan aktifitas yang bermanfaat untuk peningkatan kekuatan otot kaki, Seperti aktivitas berjalan jinjit ( heel up), berjalan dengan tumit ( toe up) saat masuk ke kelas, memonitor penggunaan medial arch support sehingga dapat melaksanakan deteksi dini dan pencegahan terjadinya flat foot dengan tujuan akhir adalah membantu pengentasan masalah flat foot di masyarakat. Dalam upaya pencegahan flat foot di masyarakat, selain peran orang tua, guru juga peran profesi ortotik prostetik bekerja bersama dalam tim rehabilitasi di Rumah Sakit.

\section{METODE PENELITIAN}

Jenis penelitian adalah quasy experimental dengan one group pre and post test design. Penelitian ini dilakukan di beberapa sekolah dasar dilingkungan Kecamatan Ngemplak Kabupetan Boyolali yaitu SDN Giriroto I, SDN Sindon I dan SDN III Manggung pada bulan Maret sampai dengan bulan Juli 2017. Sampel dalam peneltian ini 32 guru kelas dan 32 siswa usia $6-8$ tahun. Variabel independen adalah efektifitas peran guru. Variabel dependen adalah deteksi dini flat foot. Teknik sampling pada penelitian ini adalah purposive samplin. Teknik pengumpulan data menggunakan data primer dan studi pustaka. Analisis data menggunakan regresi linear dan uji $\mathrm{T}$.

\section{HASIL PENELITIAN}

Hasil analisis deskriptif sampel penelitian data kontinu dapat dilihat pada tabel 1.

Tabel 1.

Karateristik Sampel Data Kontinu

\begin{tabular}{lccccc}
\hline Variabel & $\mathrm{N}$ & Min & Max & Mean & SD \\
\hline $\begin{array}{l}\text { Umur } \\
\begin{array}{l}\text { Guru } \\
\text { Lama }\end{array}\end{array}$ & 32 & 22 & 54 & 33,13 & 10,41 \\
mengajar & 32 & 1 & 20 & 7,56 & 4,98 \\
\hline
\end{tabular}

Tabel 1. menunjukkan bahwa ratarata umur guru adalah 33 tahun, dan lama mengajar yaitu rata-rata selama 7 tahun. 
Tabel 2.

Karakteristik Sampel Data Kategorikal

\begin{tabular}{ccc}
\hline Jenis Kelamin Siswa & $\mathrm{N}$ & $\%$ \\
\hline Laki-laki & 18 & 56,2 \\
Perempuan & 14 & 43,8 \\
Jenis Kelamin guru & & \\
Laki-laki & 15 & 26,9 \\
Perempuan & 17 & 53,1 \\
Kelompok Kelas Siswa & & \\
Kelas satu & 16 & 50,0 \\
Kelas dua & 16 & 50,0 \\
\hline
\end{tabular}

Tabel 2 menunjukkan bahwa mayoritas jenis kelamin siswa adalah lakilaki sebanyak 18 orang $(56,2 \%)$, jenis kelamin guru mayoritas perempuan sebanyak 17 orang $(53,1 \%)$, dan kelonmpok kelas adalah sama yaitu kelas dua dan kelas satu (50\%).

a. Pengaruh Efektifitas Peran Guru

Sebelum dan Setelah Intervensi

Hasil pengaruh efektifitas peran guru sebelum dan sesudah intervensi dapat dilihat pada tabel 3 .

\section{Tabel 3.}

Pengaruh Efektifitas Peran Guru Sebelum dan Setelah Intervensi

\begin{tabular}{lllll}
\hline \multicolumn{1}{c}{ Variabel } & Mean & $\begin{array}{c}\text { Norm } \\
\text { alitas }\end{array}$ & $\begin{array}{c}\text { Z } \\
(\mathrm{t})\end{array}$ & $\begin{array}{c}\text { P } \\
\text { value }\end{array}$ \\
\hline $\begin{array}{l}\text { Peran } \\
\text { Guru }\end{array}$ & & & & \\
Pre test & 8,20 & 0,002 & $-4,061$ & 0,000 \\
Post test & 17,50 & 0,013 & & \\
\hline
\end{tabular}

Tabel 3 menunjukkan rata-rata peran

guru pada kelompok pre test $(8,20)$ sedangkan rata-rata peran guru pada kelompok post test $(17,50)$. Hasil uji statistik dengan Wilcoxon menunjukkan $p$ value $0,000<0,05$ sehingga terdapat pengaruh peran guru sebelum dan setelah intervensi.

b. Pengaruh Keseimbangan Dinamis pada Anak Flatfoot Sebelum dan Setelah Intervensi

Hasil penelitian pengaruh keseimbangan dinamis sebelum dan sesudah intervensi dapat dilihat pada tabel 4.

Tablet 4.

\begin{tabular}{|c|c|c|c|c|}
\hline \multicolumn{5}{|c|}{$\begin{array}{c}\text { Pengaruh Keseimbangan Dinamis pad } \\
\text { Anak Flatfoot Sebelum dan Setelah } \\
\text { Intervensi }\end{array}$} \\
\hline Variabel & Mean & $\begin{array}{l}\text { Norm } \\
\text { alitas }\end{array}$ & $\mathrm{T}$ & $\begin{array}{c}\mathrm{P} \\
\text { value }\end{array}$ \\
\hline $\begin{array}{l}\text { Keseimba } \\
\text { ngan } \\
\text { dinamis }\end{array}$ & & & $-6,378$ & 0,000 \\
\hline Pre test & 6,61 & 0,980 & & \\
\hline Post test & 7,99 & 0,053 & & \\
\hline
\end{tabular}

Tabel 4 menunjukkan rata-rata keseimbangan dinamis pada kelompok pre test $(6,61)$ sedangkan rata-rata keseimbangan dinamis pada kelompok post test $(7,99)$. Hasil uji statistik dengan Paired Sample T-test menunjukkan $p$ value $0,000<0,05$ sehingga terdapat pengaruh keseimbangan dinamis sebelum dan setelah intervensi.

c. Pengaruh Efektifitas Peran Guru terhadap Suspect Flatfoot

Hasil Efektifitas peran guru terhadap skrining suspect flatfoot dapat dilihat pada tabel 5 .

Tablet 5.

Pengaruh Efektifitas Peran Guru terhadap Suspect Flatfoot

\begin{tabular}{lccccl}
\hline & \multicolumn{5}{c}{ CI 95\% } \\
Variabel & $\beta$ & $\mathrm{T}$ & $\begin{array}{l}\text { Batas } \\
\text { bawah }\end{array}$ & $\begin{array}{l}\text { Batas } \\
\text { atas }\end{array}$ & $\mathrm{p}$ \\
\hline Constant & 1,51 & 0,59 & $-3,68$ & 6,69 & 0,55 \\
& & & & & 7 \\
Peran & 0,09 & 2,56 & 0,02 & 0,16 & 0,01 \\
guru & & & & & 6 \\
N observasi : 32 & & & &
\end{tabular}

Adjusted $\mathrm{R}^{2}: 15,2 \%$

Hasil analisis yang tampak pada

Tabel 5. memberikan informasi bahwa nilai konstan sebesar 1,51 merupakan peran guru awal yang dimiliki oleh sampel. Sedangkan nilai $\mathrm{R}^{2} \quad 15,2 \%$ menunjukkan bahwa sebanyak 15,2\% variasi-variasi dalam peran guru sesudah 
pemberian intervensi dapat dijelaskan oleh variabel-variabel intervensi dan peran sebelum perlakuan.

Hasil $\rho=0,016$ menunjukkan bahwa variabel-variabel yang tercantum dalam tabel tersebut memberikan pengaruh yang signifikan terhadap peningkatan peran guru sesudah diberikan perlakuan, yaitu guru yang telah diberikan perlakuan berupa pembinaan tentang cara mendeteksi siswa flatfoot akan mengalami peningkatan peran lebih baik daripada sampel yang tidak diberikan perlakuan tersebut.gerak konsentrik-eksentrik otot quadriceps dan SWT berpengaruh terhadap derajat nyeri pada pasien $\mathrm{OA}$ lutut (CI : 95\%, $\mathrm{p}=0,000)$.

\section{PEMBAHASAN}

a. Pengaruh Efektifitas Peran Guru Sebelum dan Setelah Intervensi

Hasil penelitian menunjukkan ratarata peran guru pada kelompok pre test $(8,20)$ sedangkan rata-rata peran guru pada kelompok post test $(17,50)$. Hasil uji statistik dengan Wilcoxon menunjukkan $p$ value $0,000<0,05$ sehingga terdapat pengaruh peran guru sebelum dan setelah intervensi. Hal ini berarti bahwa semakin sering diberikan pelatihan dan pembinaan tentang suatu pengetahuan yang dalam hal ini adalah cara melakukan skrining atau deteksi dini siswa dengan flatfoot, maka semakin meningkatkan peran guru an khususnya guru kelas dalam memperhatikan dan memberikan pemecahan masalah yang dihadapi anak didiknya.

Peran guru terhadap deteksi dini kembali struktur kaki untuk mencegah kaki datar/flatfoot usia sekolah adalah kelainan pada tulang, otot, tendon, serta mendeteksi aktifitas kesehariannya di kelelahan ligamen (Santoso, 2011).

lingkungan sekolah, mendata serta c. Pengaruh Efektifitas Peran Guru memberikan aktifitas yang bermanfaat untuk peningkatan kekuatan otot kaki, mengingat ada beberapa jam peran dari guru yang dapat termanfaatkan untuk memberikan aktifitas yang berguna antara lain : aktivitas berjalan jinjit ( heel up), berjalan dengan tumit ( toe up) saat masuk ke kelas, memonitor penggunaan medial arch support sehingga dapat melaksanakan deteksi dini dan pencegahan terjadinya flat foot dengan tujuan akhir adalah membantu pengentasan masalah flat foot di masyarakat.

b. Pengaruh Keseimbangan Dinamis pada Anak Flatfoot Sebelum dan Setelah Intervensi

Hasil penelitian menunjukkan ratarata keseimbangan dinamis pada kelompok pre test $(6,61)$ sedangkan ratarata keseimbangan dinamis pada kelompok post test $(7,99)$. Hasil uji statistik dengan Paired Sample T-test menunjukkan $p$ value $0,000<0,05$ sehingga terdapat pengaruh keseimbangan dinamis sebelum dan setelah intervensi. Semakin baik intervensi yang diberikan pada anak dengan kasus flatfoot maka semakin baik pula keseimbangan anak sehingga anak dapat melakukan aktivitas dengan optimal.

Sebagai Orthotis Prosthesis maka penangan pada kasus flat foot adalah mengontrol penyelarasan, fungsi kaki dan anggota tubuh bagian bawah, serta digunakan untuk membatasi gerakan seperti pronasi berlebihan. Orthotik tidak hanya bekerja dengan prinsip untuk menopang arcus pedis, tetapi juga memperbaiki terhadap Suspect Flatfoot dengan alat bantu orthotik dirancang untuk 
Hasil penelitian memberikan informasi bahwa nilai konstan sebesar 1,51 merupakan peran guru awal yang dimiliki oleh sampel. Sedangkan nilai $\mathrm{R}^{2}$ $15,2 \%$ menunjukkan bahwa sebanyak $15,2 \%$ variasi-variasi dalam peran guru sesudah pemberian intervensi dapat dijelaskan oleh variabel-variabel intervensi dan peran sebelum perlakuan. Hasil $\rho=0,016$ menunjukkan bahwa variabel-variabel yang tercantum dalam tabel tersebut memberikan pengaruh yang signifikan terhadap peningkatan peran guru sesudah diberikan perlakuan, yaitu guru yang telah diberikan perlakuan berupa pembinaan tentang cara mendeteksi siswa flatfoot akan mengalami peningkatan peran lebih baik daripada sampel yang tidak diberikan perlakuan tersebut.

Peran guru akan dapat mengawali pencegahan atau deteksi dini suspect flatfoot sebelum peran orang tua. Hal ini karena perubahan deformitas flatfoot terjadi pada usia pra sekolah, maka betapa besar dan penting peran guru di Sekolah Dasar dalam mewaspadai dan mencegah terjadinya masalah ini Penelitian ini merupakan penelitian pencegahan dan perlu melibatkan peran serta guru, mengingat banyak penelitian terdahulu yang belum melibatkan guru Sekolah Dasar. Jargon edukasi dalam penelitian ini adalah peduli dan waspada sejak awal pada kaki anak didik sehiungga dapat membantu pencegahan flatfoot disekolah dengan memberi kegiatan yang dapat meningkatkan lengkung arcus kaki kearah normal sehingga tercapai keseimbangan dinamis.

\section{KESIMPULAN DAN SARAN}

Flatfoot keadaan kaki datar yang mengakibatkan penderitanya sulit berjalan cepat dan gampang capek dan akhirnya menggangu aktifitas. Kepada pasien dengan hal tersebut dapat dicegah dengan pemberian aktifitas penguatan otot yang bermasalan serta pemberian alat $\mathrm{OP}$ medial archsupport. Alat ini dimasukkan sepatu penderita dan dipakai saat aktifitas disekolah setiap hari. Penelitian ini dilakukan untuk mengetahui efektifitas peran guru dalam deteksi dini Flatfoot.

Kesimpulan dari penelitian ini didapatkan hasil bahwa terdapat pengaruh yang positif dan secara statistik signifikan antara peran guru terhadap deteksi dini flatfoot di usia 6 sampai 8 atau sekolah dasar kelas 1 dan 2.

Berdasarkan penelitian ini,yang menunjukkan hasil kelengkungan yang meningkat dari telapak kaki para siswa yang menjadi responden penelitian,serta peran guru dalam intervensi pada flatfoot yang efektif sehingga saran dari peneliti adalah sebagai berikut :

1. Institusi

Sebaiknya diberikan pendidikan dan pelatihan program deteksi dini flatfoot di institusi Sekolah Dasar agar dapat sedini mungkin meminimalkan terjadinya kasus flatfoot pada anak usia 6 - 8 tahun.

2. Peneliti lain

Sebaiknya melakukan pengembangan dari penelitian yang telah ada dengan cara memperbanyak sampel penelitian dan juga menambah lokasi sehingga hasil penelitian dapat digerenalisasikan pada lokasi yang lain.

\section{DAFTAR RUJUKAN}

Ferry D.T.,2006, Flat feet in Childhood, http//:_files /Nakita Panduan Tumbuh Kembang Balita.., httm accessed Juni 2006. 
Michelson dkk, 2002, Investigation into the fat pads of the sole of the foot ankle, $13 ; 227$

Pudjiastuti , S. S., Zubaidi, A., \& W, S. D. , 2012; . Penggunaan Medial Arch Support Dan Keseimbangan Dinamis Pada Kondisi Flat Foot. Jurnal Terpadu Ilmu Kesehatan, Jilid 1, Mei 2012, 84-88.

Wall et al, 2000, The Time Up and Go test Revisite,Meusurement of the component task , From WWW,Rehabresearch,com.

Penggunaan Medial Arch Support dan keseimbangan dinamis pada kondisi flat foot. ( Sri Surini Pudjaistuti et all, 2012 ) 